\title{
Análise das narrativas sobre a menopausa de um site brasileiro da internet*
}

Marco Antonio Separavich ${ }^{1}$ Ana Maria Canesqui²

SEPARAVICH, M.A.; CANESQUI, A.M. Analysis of the narratives on menopause of a Brazilian website. Interface - Comunic., Saude, Educ., v.16, n.42, p.609-22, jul./set. 2012.

This investigation analyzes the representations and experiences concerning menopause contained in the Brazilian website Menospausa - o site da mulher Madura, an interactivity space. It identifies climacteric/menopause aspects, as well as aspects of the experience of this process and of care actions. Ten short narratives were selected among the 48 posts, and they were analyzed according to Michael Bury's classification as: contingent, progressive, moral, epic/ heroic and regressive/tragic. It is concluded that, although menopause carries common body signals, the representations and experiences that are narrated about this body, menopause and care interact with medical and nonmedical knowledge, are heterogeneous, not necessarily negative and they are informed by the narrators' social and cultural context; finally, they are filtered by the website's characteristics.

Keywords: Narratives. Menopause. Communication. Information. Internet.
O trabalho analisa as representações e os relatos da experiência com a menopausa contidos no site brasileiro da internet Menospausa - o site da mulher madura, no espaço de interatividade, procurando identificar aspectos do climatério/ menopausa, da vivência deste processo e das ações de cuidados. Foram separadas as 48 postagens, das quais dez escolhidas e analisadas conforme o gênero de narrativas, classificadas segundo Michael Bury como: contingentes, progressivas, morais, épicas/heroicas e regressivas/ trágicas. Conclui-se que, apesar de a menopausa portar sinais corporais comuns, as representações e experiências narradas sobre corpo, menopausa e cuidados dialogam com os saberes médico e não eruditos, são heterogêneas, não necessariamente negativas, e informadas pelo contexto sociocultural mais amplo de suas protagonistas, e, em particular, filtradas pelas características do site.

Palavras-chave: Narrativas. Menopausa. Comunicação. Informação. Internet.

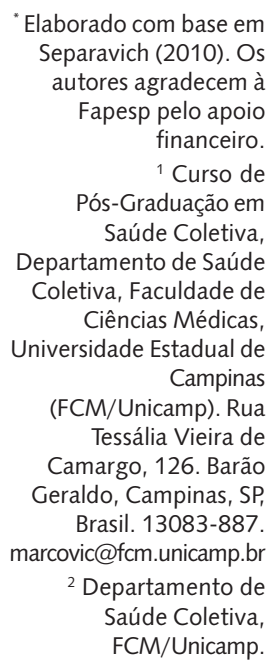

"Elaborado com base em Separavich (2010). Os autores agradecem à Fapesp pelo apoio financeiro. ${ }^{1}$ Curso de Pós-Graduação em Saúde Coletiva, Departamento de Saúde Coletiva, Faculdade de Ciências Médicas, Universidade Estadual de Campinas

(FCM/Unicamp). Rua Tessália Vieira de Camargo, 126. Barão Geraldo, Campinas, SP, Brasil. 13083-887.

marcovic@fcm.unicamp.br

${ }^{2}$ Departamento de Saúde Coletiva, FCM/Unicamp. 


\section{Introdução}

Contextualizando a menopausa historicamente, Hepworth e Featherstone (1998) esclarecem que o termo, originário da França, foi usado pelos médicos a partir do século XVIII, substituindo a concepção popular do "período de mudança da vida". Baseada nas diferenças anatômicas entre homens e mulheres, a medicina moderna concebeu os corpos femininos como mais "problemáticos" do que os masculinos, a menstruação e a menopausa vistas como patológicas, portanto, passíveis de medicalização.

Os autores informam que, ao lado da representação erudita do corpo feminino, conviviam outras formas de se conceber socialmente a menopausa. Assim, na Inglaterra do século XIX, segundo a concepção popular das mulheres, menopausa marcava a sua liberdade em função do jugo da necessidade da contracepção, da debilidade advinda do parto e da "maldição" da menstruação.

Tais representações, que se estenderam do século XIX até as primeiras décadas do XX, esculpiram uma visão ambígua da menopausa. Nos anos 1960, o entendimento de que a menopausa era uma etapa patológica da vida feminina foi retrabalhada pela medicina, com os estudos de Robert Wilson, eminente médico ginecologista dos EUA, que a definia como doença da deficiência hormonal, associando-a ao envelhecimento, e prescrevendo a reposição sistemática de estrogênio para atenuar os sintomas e manter a juventude do corpo da mulher na meia-idade (Trench, Rosa, 2008; Trench, Santos, 2005). Esta representação ainda vigora na sociedade, como se verá adiante, bem como a ambiguidade que reveste a interpretação do processo climatério/menopausa.

Para a Organização Mundial de Saúde (WHO, 1996), o climatério/menopausa é uma fase biológica, não patológica e de transição do período reprodutivo ao não reprodutivo da vida feminina. O Manual de Atenção à Mulher no Climatério/Menopausa (Brasil, 2008), do Ministério da Saúde, descreve-o como fase natural da vida das mulheres, acompanhado ou não de sintomas, como: ondas de calor, suores "frios", insônia, tristeza, instabilidade emocional, modificações nos comportamentos sexuais, na pele etc.

O Manual amplia a concepção do processo climatério/menopausa atribuindo a intensificação dos sintomas: ao ambiente sociocultural em que a mulher vive, a sua situação pessoal, como os estados psicológicos; à vida conjugal, familiar e profissional, ultrapassando a explicação do determinismo biológico inerente à diminuição de estrogênio endógeno.

Segundo estimativas do Instituto Brasileiro de Geografia e Estatística (IBGE, 2010), o Brasil tem 97 milhões de mulheres, das quais trinta milhões estão na fase do climatério/menopausa. A esperança de vida das mulheres brasileiras ao nascer é de, aproximadamente, 77 anos, o que significa que viverão um terço de suas vidas após a menopausa (Brasil, 2008), crescendo a demanda por cuidados de saúde a partir desta faixa etária (Pedro et al., 2003).

Este artigo objetiva analisar as representações e experiências nas narrativas de internautas sobre a menopausa, contidas no site brasileiro da internet Menospausa - o site da mulher madura (doravante referido como Menospausa), no espaço de interatividade, procurando identificar aspectos do climatério/menopausa que são objetos da preocupação feminina na vivência deste processo.

Segundo Laplantine (2001, p.243), representação social é "o encontro de uma experiência individual e de modelos sociais num modo de apreensão particular do real", que envolve crenças, valores, não redutíveis aos aspectos cognitivos, podendo informar a ação e associando-se a uma avaliação valorativa que articula as dimensões individual e social.

A análise da experiência da enfermidade possibilita deslindar as conexões existentes entre as sensações corporais, numa dimensão subjetiva, e o repertório de significados socioculturais disponíveis ao sofredor, capazes de atribuir sentido ao seu sofrimento, numa dimensão objetiva (Alves, 1993).

Este tipo de análise costuma centrar-se em algumas enfermidades, não como eventos patológicos definidos pelo saber biomédico, que, na literatura anglo-saxônica de ciências sociais em saúde, corresponde à categoria "disease", diferenciada de "illness", que é a percepção subjetiva dos sujeitos. É neste último sentido que, neste artigo, apresenta-se a experiência das mulheres na menopausa, concebida como entidade não patológica, que abarca narrativas diversas em torno dessa condição feminina, que, não sendo homogênea, é vivida diferentemente pelas mulheres. 


\section{Menopausa e internet na literatura}

Nas revisões da literatura de ciências sociais e humanas em saúde no Brasil, constatou-se maior interesse: nos estudos da etapa da vida reprodutiva da mulher, na sexualidade e contracepção, nas políticas de saúde, e no comportamento sexual, prevenção e controle da Aids (Canesqui, 2007; Nunes, 2006). O primeiro autor comparou os diferentes estudos feitos, e a segunda partiu dos temas de interesse de 154 cientistas sociais informados no I Catálogo Brasileiro de Cientistas Sociais da Abrasco, 1995. Percorreu a produção acadêmica nas décadas de 1980 e 1990, aparecendo Saúde Reprodutiva, Sexualidade e Gênero como assuntos emergentes, cobrindo apenas $4 \%$ do total informado, sem que menopausa e climatério tivessem sido pesquisados.

Uma nova revisão daquela literatura para o período 1997-2007, na base eletrônica de dados Scielo (Canesqui, 2010), identificou que, na década de 2000, persistiu o interesse na saúde reprodutiva, sexualidade e, sobretudo, gênero, acrescentando-se assuntos como: aborto e sua descriminalização, violência contra mulheres, perdas fetais, climatério/menopausa, masculinidades e saúde do homem, análises históricas do pensamento médico sobre a sexualidade e obstetrícia, e gênero feminino.

Para este texto, consultou-se com a palavra menopausa aquela base de dados, encontrando-se 192 artigos, dos quais 19 foram publicados nas revistas de Saúde Pública/Saúde Coletiva, e destes, apenas sete usaram referenciais das ciências sociais e humanas, sobressaindo as análises da experiência e das representações sociais da menopausa entre mulheres de baixa renda, das políticas de atenção integral à saúde da mulher, indicando-se o baixo interesse na assistência psicológica e nas informações sobre a menopausa às mulheres atendidas no Sistema Único de Saúde (Mori, Coelho, Estrela, 2006).

$\mathrm{Na}$ investigação das representações sociais sobre a menopausa, distinguem-se dois polos fundamentais: a ideia de perdas social, biológica, psicológica, e do poder de autocuidado com o corpo (Mori, Coelho, Estrela, 2006; Mendonça, 2004); e a conexão imediata entre o processo biológico do climatério/menopausa e o envelhecimento (Trench, Rosa, 2008; Costa et al., 2006; Trench, Santos, 2005).

Excepcionalmente, as análises focaram os múltiplos interesses envolvidos na medicalização da menopausa, entendida como processo crescente pelo qual as empresas farmacêuticas e a mídia especializada favorecem a criação de certos problemas de ordem médica e social, tratando-se, em muitos casos, de estados de saúde pouco conhecidos, que ganham visibilidade pública, ou de problemas anteriormente vistos como pertencentes aos ciclos naturais da vida (Moynihan, Wasmes, 2007).

Um artigo de Rozenfeld (2007) mostrou quanto os médicos, a indústria farmacêutica e as próprias mulheres propagam e endossam a terapia hormonal. Os seus riscos são silenciados, pela indústria farmacêutica, aos médicos, padecendo as mulheres da falta de informação. Além disso, os resultados de duas meta-análises, com ensaios randomizados (sendo um deles da década de 1990), alertaram para a possibilidade do aumento do risco de doenças cardiovasculares e desproteção para esses eventos pelo uso da terapia de reposição hormonal (Humphrey, Chan, Sox, 2002; Meurer, Lena, 2002).

Não há, nesta literatura, estudos sobre o uso da internet para a menopausa. São incipientes os estudos desta nova tecnologia midiática, no Brasil, para outras condições de adoecimento ou de saúde, exceto para a anorexia, cuja investigação das comunidades virtuais mostrou que elas criam identidade e um estilo de vida entre seus participantes (Ramos, Pereira Neto, Bagrichevisky, 2011). O anonimato introduz aspectos positivos, à medida que não impõe bloqueios sociais, favorecendo a interação livre de posição social, econômica, etnia e bairro (Baldanza, 2006).

Citando Hall (1997), Garbin (2003) admite que a mídia eletrônica pode mudar comportamentos, ampliar as relações sociais, alterar o espaço e o tempo. Anula as distâncias entre as pessoas, deslocando-as da vida local. Ela oferece um espaço de trocas, de sociabilidade, busca de informação, propicia encontros e a produção de conhecimento.

O "paciente expert" procura, cada vez mais, na internet, informações sobre: diagnósticos, sintomas, doenças, medicina, tratamentos e custo de atenção médica. Sua relação com os médicos e a medicina é controversa: de um lado, é consumidor de produtos e serviços de saúde; de outro, transforma a relação médico-paciente. Neste último sentido, três tipos de interferências são apontadas na literatura: a 
promoção da desprofissionalização do médico; a relação baseada na sua autoridade e/ou o abalo do seu status, reforçando a racionalidade médica (Garbin, Pereira Neto, Guilam, 2008).

A literatura menciona o comprometimento dos sites com os poderosos interesses da indústria farmacêutica, das grandes empresas, das instituições e escolas médicas, reforçando os discursos dos profissionais da biomedicina (Nettleton, Burrows, O'Malley, 2005; Seale, 2005). A ausência de neutralidade deles e a presença de interesses são bastante plausíveis.

\section{Metodologia}

Dados da Pesquisa Nacional por Amostra de Domicílios (PNAD) 2009 (IBGE, 2010 ) mostraram um aumento de $112 \%$ no acesso à internet nos últimos cinco anos. No presente trabalho, interessa destacar o acesso das mulheres nas seguintes faixas etárias: de quarenta a 49 anos, 31,9\%; cinquenta anos ou mais, $46,1 \%$. Entre as internautas do site que informaram suas idades (35,5\%), $7 \%$ estão na faixa de cinquenta anos ou mais, e $3 \%$ entre os quarenta e 49 anos.

O ambiente virtual é campo para a análise de representações e vivências da menopausa à medida que fornece a linguagem interativa entre o homem e a máquina, e possibilita a mediação digital entre a percepção e a ação (Lévy, 1996).

As comunicações nas comunidades virtuais, dos sites, blogs, fóruns e outros meios, começam a despertar o interesse de pesquisadores como fontes de informação que fogem às tradicionais e usualmente empregadas nas ciências sociais e humanas e nas investigações qualitativas em saúde, entre elas, o uso de etnografia e a análise de conteúdo das mensagens. Esta investigação segue este caminho, introduzindo a análise das narrativas.

O site Menospausa é um espaço virtual de jornalismo independente, de informação e aconselhamento do processo climatério/menopausa às mulheres maduras. Para encontrá-lo, utilizou-se o Google, provedor de serviços de busca de maior acesso mundial na internet, por meio dos descritores: mulher, menopausa, moda. Eles permitiram selecionar previamente sites contendo: representações sobre a mulher na menopausa, elementos do estilo de vida (moda), marcadores de valores sociais sobre menopausa e envelhecimento. Dentre alguns sites, escolheu-se o Menospausa a partir de uma leitura e análise exploratórias do seu conteúdo.

Extraíram-se as mensagens contidas na última atualização do site (2006), somando-se 48 textos postados em temas específicos, assim distribuídos: ondas de calor, 45,8\%; controle de peso, 18,7\%; insônia, 18,7\% ; problemas com a pele, 4,3\% ; reposição, 8,3\%, e libido, 4,2\% .

As postagens foram analisadas na forma de narrativas; estas, segundo Bury (2001), despertam o interesse das humanidades e das ciências da vida como instrumento de investigação do cotidiano dos sofredores, suas estratégias na administração dos cuidados com a saúde, as condições que afetam suas identidades e projetos de vida.

O autor define narrativa como a forma pela qual os sujeitos se apresentam para o mundo e diante de si mesmos, sendo performativa. A ação torna-se inteligível tanto para o "eu" como para os outros, integrando-se, assim, ao contexto social amplo. A despeito do caráter virtual do espaço de produção das narrativas e das interações, estas características não se alteram, sendo asseguradas pelo anonimato e maior igualdade, como discutido anteriormente.

Good e Del Vecchio (1994) apontam a diversidade e maleabilidade das narrativas. Definem narrativas breves como reveladoras dos momentos terríveis das crises; das quedas; da busca de tratamento e contatos com o sistema médico, nos momentos marcantes nos lugares públicos, e sobre os medos e sustos que poderão advir com as enfermidades. As narrativas sobre eventos e as experiências podem ser recontadas em função das interpretações das pessoas e da audiência presente. As narrativas postadas são mais circunscritas quanto aos eventos que abarcam. Elas são concisas, seus enredos obedecem a uma sequência facilmente identificável, contendo começo, meio e fim - características estas das narrativas breves, segundo Silva e Trentini (2002). Aplicam-se às mensagens postadas.

Das 48 narrativas, dez foram selecionadas, pelos seus estilos, em: contingentes, progressivas, morais, épicas/heroicas e regressivas/trágicas, segundo a classificação de Bury (2001). Para este 
autor, as diferentes formas de apresentação do "eu" constituem "gêneros" também distintos de narrativas. Assim, na análise delas importa menos saber se a exposição do "eu" se deu de modo consciente ou não, do que atentar para o seu núcleo central, isto é, aquilo que a torna singular. A questão principal é, se as fontes culturais disponíveis são múltiplas, por que o narrador elege determinada forma narrativa para se apresentar, enunciando, assim, sua experiência e aflições?

Para responder esta questão, o analista não deve descartar as ambiguidades e complexidades que envolvem as narrativas, porém, os diferentes gêneros de narrativas sintetizam a interação entre o contexto sociocultural mais amplo e a experiência peculiar do sofredor, realçados por meio de características básicas identificadas nos relatos (Bury, 2001). No caso da internet, é preciso caracterizar o site, que é o espaço onde se produzem as narrativas, não estando isentas dos direcionamentos administrativos, da influência do saber médico e dos médicos, e de interesses associados.

\section{Resultados e discussão}

\section{Contextualizando o site Menospausa}

O Menospausa é hospedado pelo provedor UOL - Universo Online, com forte penetração midiática no eixo Rio-São Paulo. Seu nome é sugestivo: contrapõe-se à representação social do senso comum, a noção de que a menopausa dá início ao envelhecimento da mulher. Nas sociedades ocidentais, a imagem da velhice é negativa, associada à dependência, à enfermidade, à passividade, à deterioração e às ideias de encargo e ruptura (Bronfman, 2005).

Dos nove membros componentes da equipe, seis são médicos, quatro são ginecologistas, um mastologista, cuja especialidade é a cirurgia plástica da mama, e uma homeopata. A editora-chefe do site é jornalista, e as demais integrantes apoiam visual e administrativamente o ambiente virtual. Menospausa é um espaço de divulgação do saber biomédico, e, simultaneamente, de troca das internautas entre si, e destas com os médicos.

O site se apresenta da seguinte forma: do lado esquerdo, numa pequena coluna, encontram-se listados assuntos relativos à menopausa, como: mudanças hormonais, secura vaginal, incontinência urinária, falta de "tesão", insônia, calores, suores, tristeza e depressão, ganho de peso e pele \& osso, dentre outros, e terapias de reposição hormonal, alimentação \& exercícios, exames \& prevenção, com as respectivas explicações biomédicas.

No espaço à direita, encontram-se várias colunas: destaque da semana; informações sobre moda \& menopausa, o espaço para especialistas, o canal da SOBRAC (Associação Brasileira do Climatério), exclusivo para médicos, cujo acesso requer identificação e o número do CRM, e MaisInteração, que possibilita à internauta "conversar" com o especialista, trocar experiências com outras pessoas e avaliar seus sintomas.

Esta seção é subdividida em tópicos relacionados como problemas da menopausa, tais como: ondas de calor, controle de peso, insônia, problemas com a pele, reposição hormonal e libido. Há várias respostas de uma amiga à outra, divididas segundo as subseções, constando apenas o nome e, eventualmente, a idade da autora da postagem. Percebe-se a quem se dirigem as respostas, pois as internautas colocam o nome da amiga correspondente.

Há muitas informações sobre a estética do corpo feminino na menopausa, com dermatologistas esclarecendo os cuidados com o rosto e corpo, divulgando técnicas de rejuvenescimento, como botóx (toxina da botulina), laserterapia, dentre outras, cujos resultados prometem ou reforçam a ideia de que é a partir da pele que se trava a luta contra o envelhecimento, pois é a face visível tanto da beleza quanto da feminilidade. Nas laterais das páginas, há anúncios sobre promoções em clínicas de estética, com formas de pagamento facilitado e serviços ginecológicos e de homeopatia ofertados.

O aspecto dialógico se sobrepõe no estilo fórum, ambiente comum na internet, inscrevendo-se na lógica interativa e dando-lhe sentido, Menospausa estimula esta interatividade, encorajando as internautas a participarem, a contarem suas experiências. 


\section{Análise dos estilos de narrativas}

Narrativas contingentes: a irrupção dos sinais corporais da menopausa, seus significados socioculturais e as estratégias utilizadas

Segundo Bury (2001), narrativas contingentes são aquelas que falam sobre as causas das enfermidades, dos problemas de saúde, dos sintomas e dos seus efeitos imediatos na vida cotidiana dos sofredores, contados por eles mesmos.

No Menospausa, os sintomas vasomotores - os fogachos - são os mais destacados pelas internautas, portadores de desconforto e constrangimento, como nas duas narrativas a seguir:

Cara [amiga]

Quando comecei a sentir os calores, aos 45 anos (hoje, tenho 55), achei que enlouqueceria. O sintoma era muito forte e freqüente como o seu...

Tenho 52 anos e comecei a ter as ondas de calor há 2 anos [...] Meu marido achava engraçado porque às vezes eu ficava desconcertada, sorrindo nervosamente e ele sentia o calor na minha pele. Mas há um mês tudo mudou. As ondas passaram a acontecer a cada 2 horas mais ou menos e se tornaram além de desconfortáveis, inconvenientes e começaram a atrapalhar a minha rotina, inclusive o sono. Diminuí café e refrigerantes e mantive os exercícios que muito me ajudaram no início da menopausa, mas nada. Há 2 semanas estou tomando um hormônio (leve, segundo meu médico) e já melhorei, consegui voltar à minha rotina.

Irrompendo de forma intensa, os sintomas são vistos como inadequados, atrapalham a vida, a rotina das ocupações sociais; o ritmo biológico do corpo, como o processo sono-vigília. O constrangimento experimentado pela narradora - aliás, sentimento social por excelência -, caracteriza aquilo que Trench e Santos (2005) chamam de visibilidade de um "não-evento". Para as autoras, a menopausa, durante muito tempo, foi um acontecimento invisível, sendo que, em nenhuma sociedade, há ritos de passagem para esta etapa da vida. Paradoxalmente, na contemporaneidade, a publicização da menopausa expôs, sobretudo no Ocidente, os signos corporais que a associam ao envelhecimento feminino. Para muitas mulheres, numa sociedade onde se cultua o corpo jovem, magro, sexy e belo, como atributos mais valorizados da feminilidade, envelhecer é desconcertante.

A biomedicina atribui à deficiência hormonal a causa principal da menopausa, originando os sintomas, que podem ser atenuados pela reposição dos hormônios. Trata-se de estabelecer a ordem orgânica num processo corporal que se encontra em desequilíbrio e descontrole. Simbolicamente, é a luta entre a ordem e a desordem, o corpo representado como a instância primeira de ordenação do mundo, sem a qual só nos restará a loucura e o caos (Geertz, 1989).

Para além do corpo como matriz simbólica e dos processos corporais como significados urdidos na trama social, as narrativas contingentes enunciam as estratégias pessoais numa dimensão mundana, isto é, como os indivíduos mobilizam recursos do ambiente social em que vivem para a mitigação dos seus problemas de saúde (Bury, 2001).

O próprio site é exemplar do uso da estratégia, pois são muitos os conselhos e as solicitações de dicas para o alívio dos sintomas do climatério/menopausa. As narrativas breves a seguir, novamente referentes aos fogachos, apontam essas duas situações:

Cara, [amiga],

Vou tentar dividir com você a experiência que funcionou para mim e para outras mulheres que conheço. Converse com seu médico e tome vitamina $E, 400$ miligramas, duas vezes ao dia. Aumente também o consumo de vitamina C. Abuse dos chás de ervas, adoce-os com stévia (você encontra em casas de produtos macrobióticos). Esta combinação acabou definitivamente com meus calores. Atualmente só sinto a onda uma vez por dia de manhã bem cedo antes de levantar da cama. Não acho que os chás tenham muito a ver com isso, 
mas as vitaminas já eliminaram os calores de outras mulheres que eu conheço. Para mim, os resultados vieram 48 horas depois das vitaminas! Boa sorte!

O que vocês sentem de ondas de calor eu sinto de frio, comigo é ao contrário. Tenho 50 anos faço reposição hormonal, uso o gel e o óvulo, emagreci o que eu tinha engordado antes da reposição $(25 \mathrm{~kg})$, só que eu tenho frio, muito frio mesmo. Espero que alguém tenha alguma dica para mim. Obrigada!

Na primeira narrativa, a internauta, atendendo ao pedido de uma amiga, relata sua experiência com os calores e como conseguiu aliviar os sintomas, conjugando elementos das concepções erudita e leiga no tratamento dos fogachos. Atribui maior eficácia ao saber médico hegemônico, que é corroborado por outras conhecidas que utilizaram somente a terapia biomédica e obtiveram o mesmo alívio. No entanto, não descarta o poder da eficácia de vitaminas, que é um elemento que permeia a cultura popular, representando a fortificação do corpo, e o que é bastante explorado contemporaneamente pela indústria farmacêutica, propagando as virtudes do consumo dos vários tipos de vitaminas.

Vários autores (Canesqui, 2007; Bury, 2001; Alves, 1993) observam que a experiência do sentir-se enfermo é influenciada tanto pelos saberes eruditos quanto pelos tradicionais e religiosos, num processo que inclui, ainda, crenças, valores, que, reelaborados pelo indivíduo, lhe permitem conferir sentido aos sintomas percebidos.

Na segunda narrativa, apesar de fazer reposição hormonal, a narradora refere experimentar ainda os sinais climatéricos que, de forma diversa da maioria, são traduzidos por ondas de frio que percorrem o corpo. É uma narrativa mais medicalizada, correspondendo a tratamentos de reposição hormonal bastante recomendados pela medicina, embora com maiores restrições atuais do que no passado, por suas consequências adversas sobre a saúde da mulher. Ressalta-se que a internauta se reporta a um efeito positivo da reposição hormonal sobre o seu corpo, pelo emagrecimento, que é um ideal de corpo aprovado socialmente em contraposição ao corpo gordo, reprovado.

Natansohn (2005) sublinha a importância da mídia na divulgação dos padrões corporais e estéticos, tornando-se o corpo feminino objeto médico e "midiático", retratado em programas de televisão de audiência nacional, nas teleconsultas médicas. Neste espaço, reiteram-se os imperativos estéticos, aparecendo o corpo como "âncora da mulher, sua razão de ser, para si mesmo e para o outro e seu desejo" (Natansohn, 2005, p.288).

O acesso às diferentes informações de saúde localiza os problemas com a menopausa dentro de um processo de mudanças sociopsicofisiológicas características desta fase. Sendo processual, o climatério/ menopausa pode ser definido tendo começo, meio e fim. As narrativas abaixo evidenciam tal entendimento:

Tenho 54 anos e estou quase no fim (acho eu!) do processo da menopausa. Tenho vários sintomas, mas pelo que tenho lido parece que são os calores que mais afligem a todas.

Estou com 45 anos, farei 46 agora dia 18/02. Há 1 ano fiz exames e realmente foi detectado que estava fazendo a menopausa.

Estas narrativas desvelam a influência do saber erudito na representação destas internautas sobre a menopausa, quer seja pela periodização do processo e a classificação dos sintomas tal como concebidos pela biomedicina, quer seja pelo entendimento de suas causas, como manifesto no segundo relato: é o próprio corpo que "faz" a menopausa.

\section{Narrativas progressivas}

São aquelas que revelam uma dimensão mais profunda, entrecruzando as relações com o corpo, os anseios pessoais e os significados socioculturais atribuídos às contingências, configurando uma forma nova de apresentação do "eu", tanto para si quanto para aqueles que convivem com o sofredor (Bury, 2001). 
A experiência do sentir-se enfermo é filtrada pelo tecido social, e a forma de narrá-la circunscrevese ao contexto cultural. Aquele que narra, ao expor sua experiência, obedece a códigos de linguagem e significação específicos, que são, ao mesmo tempo, condição para que a comunicação se dê e elementos delimitadores daquilo que é dito. Isto não impede os componentes criativos das narrativas, uma vez que o repertório cultural é variado e dinâmico, em permanente reelaboração.

As narrativas progressivas apresentam o indivíduo positivamente, o núcleo funda-se na positivação de eventos considerados negativos (Bury, 2001), como na postagem abaixo:

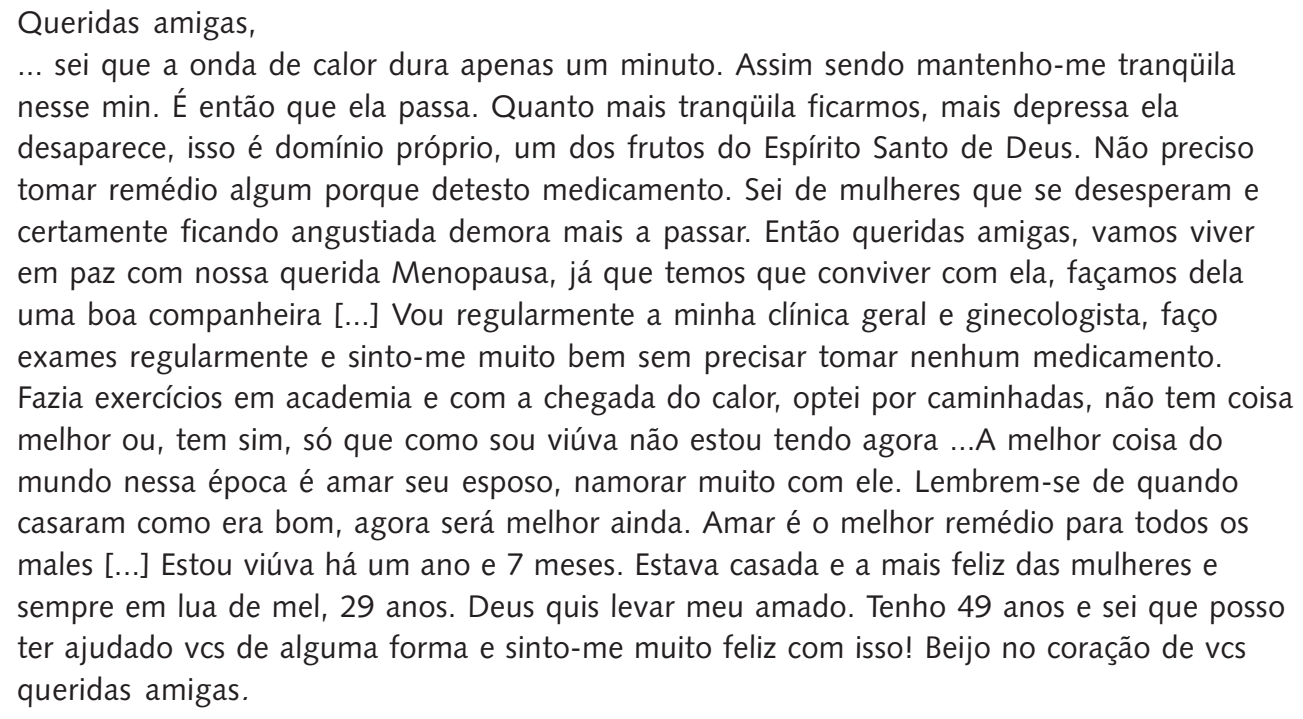

Os sinais do climatério/menopausa, a perda do marido, acontecimentos que poderiam transtornar a vida da narradora, fazendo com que o processo se desdobrasse de maneira problemática, são suavizados pela postura de autocontrole e resignação da internauta.

Há uma matriz religiosa orientando a administração e o controle do sintoma, configurando uma conduta ascética, e a ideia de comedimento e resignação diante de situações adversas. O ideal religioso é traduzido por uma disciplina sóbria das emoções e das ações daquele que crê, e a presença da divindade no cotidiano da vida é comprovada pelo fato de "manter-se saudável de corpo e alma", marcadamente baseada no ethos de uma ética protestante (Weber, 2004).

O relato se desenvolve dentro de objetivos pessoais e socialmente valorizados, como a eliminação do sintoma, o comportamento preventivo exemplar, o sentimento de amor ao próximo, numa "apresentação virtuosa do eu" que a aproxima das narrativas morais, nas quais a saúde é retratada como estado virtuoso do sofredor (Bury, 2001).

Esse "eu virtuoso" estende-se à relação da narradora com os aconselhamentos médicos, de mudanças do estilo de vida, tais como: caminhada, visita regular ao ginecologista, fazer os exames periodicamente, como forma de convívio com a menopausa. Cotejam-se essas considerações com algumas observações sobre o envelhecimento feminino fornecidas por Uchôa, Firmo e Lima-Costa (2002), sobre a positivação do processo de envelhecimento; este envolve mais a capacidade de superação dos acontecimentos dolorosos pelas pessoas, de reformulação dos projetos - estabelecendo os que lhes são fundamentais - e adaptação às mudanças que ocorrem, do que a realização de objetivos previamente escolhidos, já que estes, como a própria experiência ensina, são contingenciais.

\section{Narrativas morais}

Há narrativas nas quais a experiência com a menopausa remete à análise moral dos eventos, sendo mais bem categorizadas como narrativas morais (Bury, 2001), conforme a citada a seguir: 
Cara [amiga]

Eu tenho tido muita mudança de humor e sempre fui uma pessoa pra cima, alto astral. Quanto ao peso, faz 5 anos que me tornei membro dos vigilantes do peso. Essa questão do peso é um desafio diário. Acho engraçado que o médico também insiste que a gordura não é conseqüência da menopausa. Mas quando comecei a tomar hormônio (paxil), meu médico disse que eu não engordaria. Engordei e tive que fazer regime por conta própria. Hoje estou magra, mas não está fácil manter o peso. Às vezes acho que os médicos não têm idéia das transformações que a menopausa causa na mulher, principalmente quando o médico é homem.

A ênfase desta internauta no problema com o corpo obeso, expresso na dificuldade de se manter magra, evidencia preocupação e sofrimento constantes, transformando-se num verdadeiro "desafio". Testemunha uma "luta diária" da moralidade leiga (Bury, 2001): o esforço para atingir um determinado objetivo, no caso o corpo esbelto, é tanto mais valorizado quanto maior for o sacrifício. A sua adesão aos "vigilantes do peso", que é fator estratégico, explicita a extensão desses esforços, complementados pelo regime que realiza "por conta própria", que lhe impõe restrições físicas e morais.

É também o testemunho do comprometimento da narradora com a resolução do seu problema ideal valorizado socialmente -, onde a responsabilidade pela solução dos incômodos corporais recai sobre o sujeito, na sua aderência ao tratamento. Este ponto assinala o encontro entre profissional de saúde e paciente, e as eventuais dificuldades de comunicação entre ambos.

Apesar de o saber médico atribuir, ao climatério/menopausa, modificações no metabolismo ósseo e de lipídeos, tendendo o corpo à obesidade, a internauta sublinha o fato de o médico não ver a obesidade como consequência da menopausa, e, por extensão, não entender seus impactos na vida das mulheres. Essa dificuldade de comunicação revela diferenças de gênero, o reducionismo biomédico e a exclusão da experiência dos sujeitos.

Observa-se, finalmente, que os esforços para se manter magra e com disposição para a vida revelam a preocupação de ser conservada uma identidade anterior, fortemente apoiada na aparência corporal, nos valores a ela agregados e na postura ativa e positiva perante a vida, em meio às múltiplas transformações que ocorrem nesta fase.

\section{Narrativas épicas/heróicas}

A capacidade de aceitar e superar as várias mudanças que acontecem em suas vidas neste período inclusive a ideia da menopausa como signo social do envelhecimento feminino - e de estabelecer projetos novos, assinala uma passagem mais tranquila de algumas mulheres pelos problemas da menopausa, como expresso na narrativa abaixo:

Adorei este site, entrei na menopausa cirúrgica aos 45 anos, engordei $13 \mathrm{~kg}$. Meu médico disse que não tem nada a ver com a menô, fiz um regime a base de arroz integral e verduras e tomei cálcio, voltei ao meu peso normal e lá se vão 5 anos me mantendo nele sem nenhum sacrifício. O negócio tem muito a ver com a mente. Temos que nos conscientizarmos que não somos mais a bela da praia e passar a gostarmos de nós como estamos e procurar outros interesses na vida. E ter sempre na mente Fernando Pessoa: Tudo vale a pena se a alma não é pequena: e seguir em frente com coragem e fazendo os exames anuais sem medo de ser feliz. Afinal a menopausa dá uma enorme liberdade em muitos sentidos. Mulherada vamos ser feliz com nossa experiência!

Nesta narrativa sobressai o caráter de superação de situações adversas, retornando a internauta ao seu peso normal, mantendo-se nele "sem nenhum sacrifício." A análise indica que o "eu" pode ser concebido como forjado na vitória das adversidades e pela postura corajosa de se seguir adiante mesmo com e apesar delas, numa narrativa épica/heróica (Bury, 2001). 
Esse "eu heróico" traz consigo a ideia de não-passividade diante dos problemas e a valorização da individualidade como resposta à estereotipia do feminino, personificada, aqui, na figura da "bela da praia". Se antes, na pré-menopausa, era o corpo o objeto privilegiado "do olhar social", inclusive das próprias mulheres, agora, na menopausa, deve ser enfocada a mente como elemento-chave para a libertação feminina, tanto dos problemas da menopausa quanto do sentimento de inferioridade por não se ter mais aquele corpo-objeto. Atingir esta consciência e a autovalorização é tarefa individual, mas trata-se, acima de tudo, do empoderamento da condição feminina.

Esta narrativa contrapõe-se às contingentes que associam a menopausa a um conjunto de sensações corporais desagradáveis, a perdas, representando, de forma negativa, este período e seus efeitos comportamentais na rotina diária. Ao invés disso, a menopausa simboliza uma liberdade, embora não explicitada pela internauta. Traz a ideia de uma fase da vida que comporta experiências de ganhos e não somente de privações, tanto físicas quanto morais, afetivas e relacionais.

\section{Narrativas regressivas/trágicas}

Observam-se, ainda, narrativas nas quais os problemas com a menopausa são experimentados de forma negativa, afastando-se das metas pessoais mais comuns do cotidiano. Elas podem assumir contornos trágicos, caracterizando uma narrativa regressiva/trágica, como expresso a seguir:

Entrei na menopausa com ondas de calor terríveis. Tomo hoje comprimidos de premarim com mpa de 205mg, me sinto melhor do calor, mas em compensação minha pele envelheceu 15 anos, não sei o que faço. Não tenho condições financeiras para fazer nada, ainda. Fui largada pelo meu marido. Tenho depressões horríveis de saber que não posso melhorar a minha aparência para ao menos refazer a minha vida. Gostaria da ajuda de vcs. Se tiverem alguma sugestão caseira ou souberem de algum lugar no Rio de Janeiro onde eu pudesse ao menos pegar algumas dicas. Tenho 54 anos e pareço que tenho 70. Abraços a todas vcs!

Em oposição à narrativa anterior, a internauta relata, como situações adversas: os problemas com o envelhecimento da pele, que a faz aparentar "quinze anos" a mais; a falta de condições financeiras para reverter este quadro; o fato de ter sido deixada pelo marido, além das depressões. Esses elementos envolvem uma discordância contínua e crescente entre aquilo que se almeja e o que realmente se tem, agravada por não se ter, pelo menos momentaneamente, possibilidade de ver seus anseios atendidos, daí seu caráter regressivo (Bury, 2001).

Nesta narrativa, o fulcro são as perdas: da elasticidade da pele, de dinheiro, do marido, e da alegria de viver. A ideia de refazer a vida, segundo a narradora, passa, necessariamente, pela "melhora da aparência", que, por sua vez, só é possível se tiver dinheiro suficiente para isso, as dicas caseiras sendo paliativos. Um "eu desventuroso" se apresenta neste relato, cujo retorno à dinâmica da vida requer a manutenção das características físicas anteriores aos problemas da menopausa.

Expõe-se, assim, uma identidade fragilizada, e a ideia de que o corpo somente é valorizado por suas juventude, beleza e sensualidade, aliás, concepção afinada com o modelo socialmente difundido. Seguindo esta lógica, as perdas destas características podem trazer problemas identitários, significando a perda do sentido da própria vida.

Nota-se, na maioria das narrativas, o desconforto com o aumento do peso e os esforços das internautas para conservarem ou se aproximarem de um corpo ideal, esbelto, que se espera conquistar a partir de uma agenda diária de atividades, incluindo dietas, regimes, exercícios físicos e o desenvolvimento de um novo estilo de vida, implicando submissão ao atendimento dos aconselhamentos médicos - estes estão bem presentes na Saúde. 


\section{Considerações finais}

A análise das narrativas breves e de seus estilos, a partir das mensagens postadas pelas internautas no Menospausa, revela as singularidades dos enredos das mulheres, cujos estilos muito bem retratam as formas diferenciadas de comunicar e de apresentar o próprio "eu" e os problemas físicos, morais, afetivos e relacionais que as afligem com a menopausa, representada ambiguamente como experiência positiva e negativa.

Esta ambiguidade também pode se dar entre o descompasso do imaginário social mais amplo, da menopausa como perdas e envelhecimento, e as experiências positivas ou não das mulheres em relação a ela, traduzidas como ganhos ou privações. A lógica biologizante da medicina a torna patológica pelo deficit hormonal e consequentes alterações no funcionamento do corpo, na aparência e nas emoções, para melhor medicalizá-la e controlá-la sob o biopoder. Estas mudanças afetam o âmago da imagem da feminilidade socialmente construída e valorizada contemporaneamente em torno da aparência, juventude, beleza, do corpo perfeito, hígido, magro e sedutor.

As narrativas do site, diferentemente das obtidas pelas técnicas de entrevistas individuais ou grupais não diretivas, são menos espontâneas, além de breves, filtram-se pelos interesses editoriais e mercadológicos, mediados e subordinados ao processo de medicalização, transformando em patológico um evento da existência biológica e sociocultural de uma etapa da vida da mulher. O Menospausa serve como ambiente de troca de informações e relacionamentos entre internautas anônimas, unidas e igualadas por uma condição biossociocultural que é a menopausa, sobreposta às diferenças socioeconômicas e culturais tão relevantes nas interações sociais face a face e que são ocultadas no contexto do site.

A linguagem dos sintomas perpassa quase todas as narrativas, ao lado dos relatos sobre os eventos, condições de vida, da relação com o corpo, dos relacionamentos afetivos (viuvez, condições financeiras, preocupações com a estética corporal, atitudes perante a vida), acompanhando a reconstrução das experiências das mulheres com a menopausa, inscritas nas próprias vidas, extrapolando, portanto, os fenômenos estritamente biológicos e observados objetivamente nos corpos pela medicina.

As nuances dos estilos de narrativas, especialmente as progressivas e as heroicas, permitiram apreender que os relatos das experiências trazem a menopausa para o controle das mulheres, subtraindo ou resistindo ao da medicalização, à medida que tal experiência também pode ser liberadora e posta sob controle dos sujeitos, identificados não como objetos passivos e subordinados ao controle médico, mas como ativos, tendo a felicidade e liberdade como valores integrados às suas experiências com a menopausa.

A ampliação da concepção dos significados socioculturais do processo climatério/menopausa comporta a conexão entre corpo, normas, valores e sentidos a ele conferidos, podendo as Ciências Sociais em saúde contribuírem para um entendimento mais refinado daquele processo, colaborando para uma compreensão do corpo não somente como um conglomerado anatomofisiológico, sujeito às leis orgânicas e a uma automaticidade inexorável, mas como aglutinador de diferentes experiências e representações socioculturais de diversas fases da vida (Separavich, Canesqui, 2010).

\section{Colaboradores}

Os autores trabalharam juntos em todas as etapas de produção do manuscrito. 


\section{Referências}

ALVES, P.C. A experiência da enfermidade: considerações teóricas. Cad. Saude Publica, v.9, n.3, p.263-9, 1993.

BALDANZA, R.F. A comunicação no ciberespaço: reflexões sobre a relação do corpo na interação e sociabilidade em espaço virtual. In: ENCONTRO DOS NÚCLEOS DE PESQUISA DA INTERCOM, 6., 2006, Rio de Janeiro. Anais... Rio de Janeiro: Intercom Sociedade Brasileira de Estudos Interdisciplinares da Comunicação, 2006. p.1-15.

BRASIL. Ministério da Saúde. Secretaria de Atenção à Saúde. Departamento de Ações Programáticas Estratégicas. Manual de Atenção à Mulher no Climatério/Menopausa. Brasília: Ministério da Saúde, 2008.

BRONFMAN, E. Envejecimento y gênero: algunas reflexiones. Revista Mujer Salud, v.2, n.3, p.66-71, 2005.

BURY, M. Illness narratives: fact or fiction? Sociol. Health Illn., v.23, n.3, p.263-85, 2001.

CANESQUI, A.M. Temas e abordagens das ciências sociais e humanas em saúde na produção acadêmica de 1997 a 2007. Cienc. Saude Colet., v.15, n.4, p.1955-66, 2010.

Ciências Sociais e Saúde no Brasil. São Paulo: Hucitec, 2007.

COSTA, T. et al. Naturalização e medicalização do corpo feminino: o controle social por meio da reprodução. Interface - Comunic., Saude, Educ., v.10, n.20, p.363-80, 2006.

GARBIN, H.B.R.; PEREIRA NETO, A.F.; GUILAM, M.C.R. A internet, o paciente expert e a prática médica: uma análise bibliográfica. Interface - Comunic., Saude, Educ., v.12, n.26, p.579-88, 2008.

GARBIN, E.M. Cultur@s juvenis, identid@des e internet: questões atuais. Rev. Bras. Educ., n.23, p.119-35, 2003.

GEERTZ, C. A interpretação das culturas. Rio de Janeiro: LTD, 1989.

GOOD, B.J.; DEL VECCHIO, M.J.G. In the subjunctive mode: epilepsy narratives in Turkey. Soc. Sci. Med., v.38, n.6, p.835-42, 1994.

HALL, S. A centralidade da cultura: notas sobre as revoluções do nosso tempo. Educ. Real., v.22, n.2, p.15-46, 1997.

HEPWORTH, M.; FEATHERSTONE, M. The male menopause: lay accounts and the cultural reconstruction of midlife. In: NETTLETON, S.; WATSON, J. (Orgs.). The body in everyday life. London: Routledge, 1998. p.276-301.

HUMPHREY, L.L.; CHAN, B.S., SOX, H.C. Postmenopausal hormone replacement therapy and primary prevention of cardiovascular disease. Ann. Intern. Med., v.137, p. 273-284, 2002.

IBGE. Censo demográfico: dados federais. Brasília: IBGE, 2010. Disponível em: <http://www.censo2010.ibge.gov.br>. Acesso em: 17 out. 2010.

Pesquisa Nacional por Amostra de Domícilios (PNAD) 2009. Brasília: IBGE, 2010. Disponível em: <http://www.ibge.gov.br/home/presidencia/noticias/ noticia visualiza.php?id noticia=1708>. Acesso em: 17 out. 2011.

LAPLANTINE, F. Antropologia dos sistemas de representações da doença: sobre algumas pesquisas desenvolvidas na França contemporânea reexaminadas à luz de uma experiência brasileira. In: JODELET, D. (Org.). As representações sociais. Rio de Janeiro: EDUERJ, 2001. p.241-59.

LÉVY, P. O que é o virtual? São Paulo: Editora 34, 1996. 
MENDONÇA, E.A.P. Representações médicas e de gênero na promoção da saúde no climatério/menopausa. Cienc. Saude Colet., v.9, n.3, p.751-62, 2004.

MENOSPAUSA - o site da mulher madura. Disponível em: <http://www2.uol.com.br/ Menospausa >. Acesso em: 8 ago. 2008.

MEURER, L.N.; LENA, S. Cancer recurrence and mortality in women using hormone replacement therapy. J. Fam. Pract., v.51, n.51, p.1056-62, 2002.

MORI, E.M.; COELHO, V.L.D.; ESTRELLA, R.C.N. Sistema Único de Saúde e políticas públicas. Atendimento psicológico à mulher na menopausa no Distrito Federal.

Cad. Saude Publica, v.22, n.9, p.1825-33, 2006.

MOYNHAN, R.; WASMES, A. Vendedores de doença. In: PELIZZOLI, M. (Org.). Bioética como novo paradigma: por um novo modelo biomédico e biotecnológico. Petrópolis: Vozes, 2007. p.151-6.

NATANSOHN, G.L. O corpo feminino como objeto médico e "mediático". Rev. Estud. Fem., v.13, n.2, p.287-304, 2005.

NETTLETON, S.; BURROWS, R.; O'MALLEY, L. The mundane realities of the everyday lay use of the internet for health, and their consequences for media convergence. Sociol. Health Illn., v.27, n.7, p.972-92, 2005.

NUNES, E.D. A trajetória das Ciências Sociais em Saúde na América Latina: revisão da produção científica. Rev. Saude Publica., v.40, suppl., p.64-72, 2006.

PEDRO, A.O. et al. Idade de ocorrência da menopausa natural em mulheres brasileiras: resultados de um inquérito populacional domiciliar. Cad. Saude Publica, v.19, n.1, p.17-25, 2003.

RAMOS, J.S.; PEREIRA NETO, A.F.; BAGRICHEVSKY, M. Cultura identitária próanorexia: características de um estilo de vida em uma comunidade virtual. Interface - Comunic., Saude, Educ., v,15, n.37, p.447-60, 2011.

ROZENFELD, S. Terapia hormonal para a menopausa (TH): múltiplos interesses a considerar. Cienc. Saude Colet., v.12, n.2, p.433-42, 2007.

SEALE, C. New directions for critical internet health studies: representing cancer experience on the web. Sociol. Health Illn., v.27, n.4, p.515-40, 2005.

SEPARAVICH, M.A. Uma reflexão socioantropológica sobre o corpo na menopausa. 2010. Dissertação (Mestrado em Saúde Coletiva). Faculdade de Ciências Médicas, Universidade Estadual de Campinas, Campinas, 2010.

SEPARAVICH, M.A.; CANESQUI, A.M. Girando a lente socioantropológica sobre o corpo: uma breve reflexão. Saude Soc., v,19, n.2, p.249-59, 2010.

SILVA, D.G.V.; TRENTINI, M. Narrativas como técnica de pesquisa em enfermagem. Rev. Latino-Am. Enferm., v.10, n.3, p.423-32, 2002.

TRENCH, B.V.; ROSA, T.E.C. Menopausa, hormônios, envelhecimento. Discurso de mulheres que vivem em um bairro da periferia da cidade de São Paulo, Estado de São Paulo, Brasil. Rev. Bras. Saude Mater. Infant., v.8, n.2, p.207-16, 2008.

TRENCH, B.V.; SANTOS, C.G. Menopausa ou menopausas? Saude Soc., v.14, n.1, p.91-100, 2005.

UCHÔA, E.; FIRMO, J.O.A.; LIMA-COSTA, M.F.F. Envelhecimento e saúde: experiência e construção cultural. In: MINAYO, M.C.S.; COIMBRA JÚNIOR, C.E.A. (Orgs.).

Antropologia, saúde e envelhecimento. Rio de Janeiro: Fiocruz, 2002. p.25-35.

WEBER, M. A ética protestante e o espírito do capitalismo. São Paulo: Companhia das Letras, 2004.

WHO. World Health Organization. Research on the menopause in the 1990. Reports of a WHO scientific group. Geneva: WHO, 1996. 
SEPARAVICH, M.A.; CANESQUI, A.M. Análisis de las narrativas de la menopausia de através de la internet. Interface - Comunic., Saude, Educ., v.16, n.42, p.609-22, jul./set. 2012.

Este trabajo analiza las representaciones y las experiencias con la menopausia contenidos en el sitio brasileño de la internet Menospausa - o site da mulher madura, en el espacio de relacionamiento e interactividad, buscando identificar aspectos del climaterio/menopausia, de la vivencia de este proceso y de las acciones de cuidados. Entre 48 mensajes 10 escojidas y analizadas conforme el género de narrativas, usando la clasificación de Michael Bury como: contingente, progresivo, moral, épico/heroico y regresivo/trágico, indicaron, que aunque la menopausia tenga señales corporales comunes, las representaciones y las experiencias narradas sobre el cuerpo, menopausia y los cuidados dialogan con los saberes médicos y no eruditos, son heterogéneas, no necesariamente negativas e informadas por el contexto sociocultural más amplio de sus protagonistas.

Palabras clave: Narrativas. Menopausia. Comunicación. Información. Internet. 